\title{
Sarcomatoid Carcinoma of the Urinary Bladder: A Case Report and Review of the Literature
}

\author{
(D) Özgecan Gündoğar ${ }^{1}$, (D) Sibel Bektaş2, (1) Arif Özkan³ \\ ${ }_{1}^{1}$ Bahçelievler State Hospital, Department of Pathology, Istanbul, Turkey \\ ${ }^{2}$ Gaziosmanpaşa Health Practice and Research Hospital, Department of Pathology, Istanbul, Turkey \\ ${ }^{3}$ Koç University Hospital, Clinic of Urology, Istanbul,Turkey
}

\section{Abstract}

Sarcomatoid variant of urothelial carcinoma of the urinary bladder is a rare malignant neoplasm, which is defined with biphasic neoplasm with both an epithelial and a mesenchymal component by histopathological and immunohistochemistry. It is responsible for $0.3 \%$ off all bladder carcinomas. The aim of this study was to present the histopathological and immunohistochemical findings of a case of sarcomatoid carcinoma of the urinary bladder and to review the relevant literature. A 75-year-old man was presented to our hospital with hematuria. $6.5 \times 5.8 \mathrm{~cm}$ tumor was found in the urinary bladder at ultrasonography. Magnetic resonance imaging demonstrated a large irregular-shaped $9 \times 5 \mathrm{~cm}$ tumor involving the right posterolateral wall of the urinary bladder and an atrophic kidney. The patient underwent cystoprostatectomy, left nephrectomy, and lymph node dissection. Macroscopically, a 7.5x6.1×1.8 cm ulcero-vegetating tumor mass infiltrating the bladder base, right-left side wall, anterior-posterior wall, and trigon was seen. Microscopically, this tumor was composed of high-grade urotelial carcinoma and mesenchymal differentiation areas with a wide eosinophilic cytoplasm, vesicular nucleus, distinct nucleolus and spindle-shaped areas. Immunohistochemically, mesenchymal differentiation areas were stained prominently with vimentin, keratin. The case was diagnosed as sarcomatoid carcinoma. Tumor metastasis was detected in the prostate and in bilateral pelvic lymph nodes. Although the clinical findings and the age of diagnosis of sarcomatoid urothelial carcinoma are similiar to conventional urothelial carcinoma, it has a worse prognosis. The presented case died 2.5 months after surgery. Sarcomatoid carcinoma seems to represent the final common pathway of urothelial carcinoma dedifferentiation. Keeping this aggressive tumor type in mind is essential for a correct treatment approach

Keywords: Urinary bladder, epithelial, mesenchymal, malignant

\section{INTRODUCTION}

Sarcomatoid carcinoma of the bladder is a biphasic malignant tumor in which epithelial and mesenchymal differentiation is determined morphologically and immunohistochemically (1). According to the Surveillance, Epidemiology, and End Results (SEER) database of the US National Cancer Institute, this tumor accounts for $0.6 \%$ of all bladder tumors $(2,3)$. We presented the clinical, histopathological, and immunohistochemical findings of this tumor, which shows a much more aggressive clinical course compared to urothelial carcinoma, in the light of the literature.

\section{The Case}

A seventy-five-year-old male patient applied to our hospital's urology outpatient clinic with a complaint of hematuria. An abdominal ultrasonography revealed a $6.5 \times 5.8 \mathrm{~cm}$ mass, filling the bladder. Upon determination of a $9 \times 5 \mathrm{~cm}$ mass extending from the right posterolateral wall of the bladder and atrophy findings in the left kidney in the magnetic resonance imaging, the patient underwent cystoprostatectomy, left nephrectomy and pelvic lymph node dissection. No malignancy was observed in the intraoperative consultation of the right ureter lower end surgical margin. Macroscopic evaluation of the bladder
Address for Correspondence: Özgecan Gündoğar, Bahçelievler State Hospital, Department of Pathology, İstanbul, Turkey

Phone: +90 5353767370 E-mail: ozgecankarahan@hotmail.com ORCID ID: orcid.org/0000-0003-3075-6063
Received: 27.02 .2018 Accepted: 17.12 .2018

Cite this article as: Gündoğar Ö, Bektaș S, Özkan A. Sarcomatoid Carcinoma of the Urinary Bladder: A Case Report and Review of the Literature. Eur Arch Med Res 2020; 36 (2):150-5

๑Copyright 2020 by the University of Health Sciences Turkey, Prof. Dr. Cemil Taşçığlu City Hospital European Archives of Medical Research published by Galenos Publishing House. 
revealed a $7.5 \times 6.1 \times 1.8 \mathrm{~cm}$ ulcero-vegetating mass involving the bladder base, right and left walls, anterior-posterior walls, and the trigon. The sections of the mass were grayish in color and fragile in nature. In the lymph node dissection material, 10 right pelvic and 8 left pelvic lymph nodes were detected. Macroscopic evaluation of the left kidney, which was operated due to atrophy, revealed a dilated pelvicalyceal system, thinned cortex, and a 0.3 $\mathrm{cm}$ diameter stone in the calyx.

Histopathological evaluation of the mass revealed mesenchymal differentiation forming the majority of the tumor (Figure 1, short arrows) with wide eosinophilic cytoplasm, vesicular nucleus, prominent nucleolus, locally spindle-shaped and locally multinuclear bizarre giant cells (Figure 2) which is separated from the high grade papillary carcinoma confined to a focal area (Figure 1, long arrow) by a sharp border. In the cells showing mesenchymal differentiation, diffuse immune reaction to vimentin (Figure 3), and focal immune reactions to pancytokeratin (Figure 4, short arrow), cytokeratin 7 (CK7), and CD31 were observed. In the area showing epithelial differentiation, diffuse reactions were observed to pancytokeratin (Figure 4, long arrow), and CK7 and focal reactions were observed to CK20 (Figure 5, arrow), and epithelial membrane antigen (EMA). No reaction was observed to smooth muscle actin (SMA), muscle-specific actin, and desmin in neither epithelial nor mesenchymal areas. No reaction was observed with HCG in bizarre multinucleated giant tumor cells. In the light of these findings, the case was diagnosed as "sarcomatoid carcinoma". No tumor was observed in neither of the ureteral surgical margins. The tumor was observed to cross the bladder wall and invade the prostate. Tumor metastases were

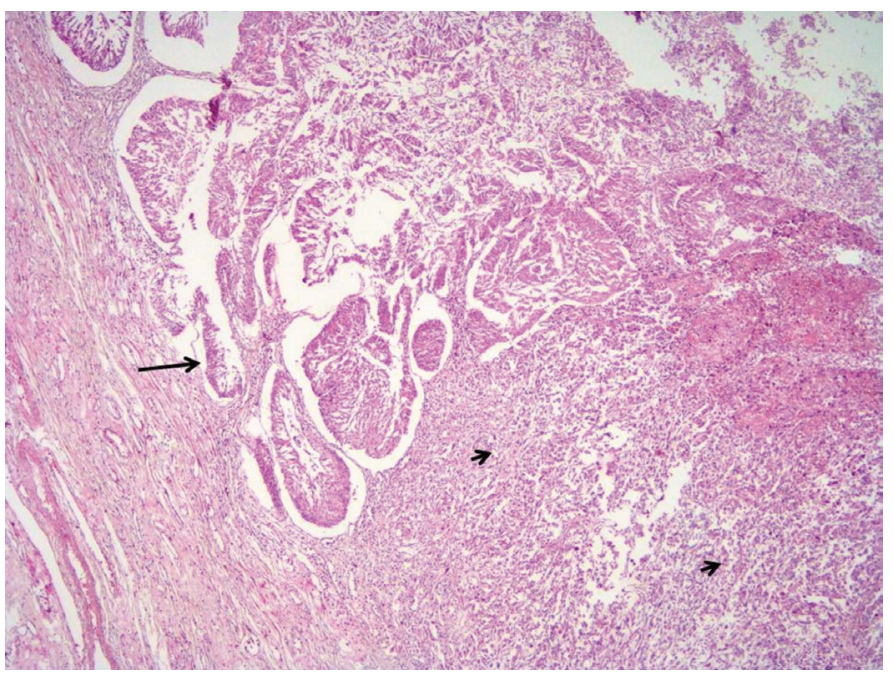

Figure 1. High grade papillary urothelial carcinoma (long arrow) and sharply demarcated mesenchymal differentiation areas (short arrows) $(H \& E \times 40)$

$\mathrm{H} \& \mathrm{E}:$ Hematoxylin and eosin observed one at right pelvic lymph node and one at left pelvic lymph node. Microscopic evaluation of the left kidney revealed chronic pyelonephritis and atrophy; tumoral infiltration was not observed. No additional treatment should be given due to the worsening of his general condition, and the patient was died 2.5 months after the operation.

\section{DISCUSSION}

Sarcomatoid carcinoma, first described in 1935, develops in many organs and tissues such as the genitourinary system, respiratory system, gastrointestinal system, hepatobiliary system, pancreas, thyroid, skin, breast, spleen, and peritoneum (4). The clinical course of these tumors seen in different organs also differ.

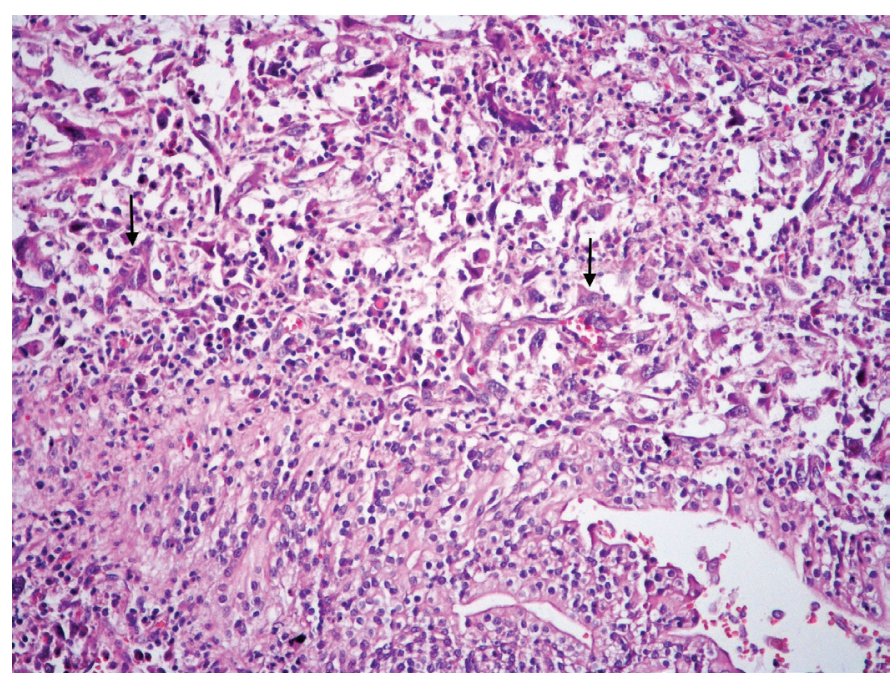

Figure 2. Multinucleated bizarre giant cells at areas showing mesenchymal differentiation (H\&E x 100)

$\mathrm{H} \& \mathrm{E}:$ Hematoxylin and eosin

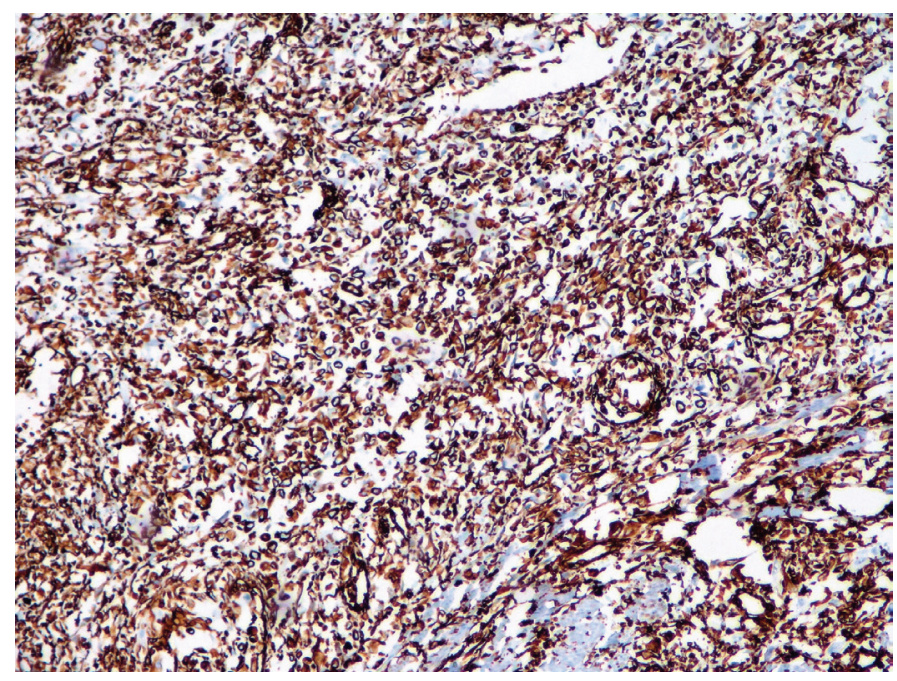

Figure 3. Diffuse immune reaction to vimentin in cells which demonstrate mesenchymal differentiation (IHK x 200)

IHK: Immunohistochemistry 
A total of 835 cases, including 522 cases in the SEER database analysis between January 1960 and January 2010, and 313 cases in 13 studies between January 2010 and 2014, were reported (5). As a result of our search using the keywords "carcinosarcoma", "sarcomatoid carcinoma", and "bladder tumor" in Pubmed database, we determined 32 more cases between February 2014 and August 2017. Thus, we detected that 867 sarcomatoid bladder carcinomas were reported in the literature between January 1960 and August 2017 (1,5-24). The clinicopathological features of these cases are presented in Table 1.

In the World Health Organization 2016 classification, "sarcomatoid carcinoma" terminology is used for all biphasic

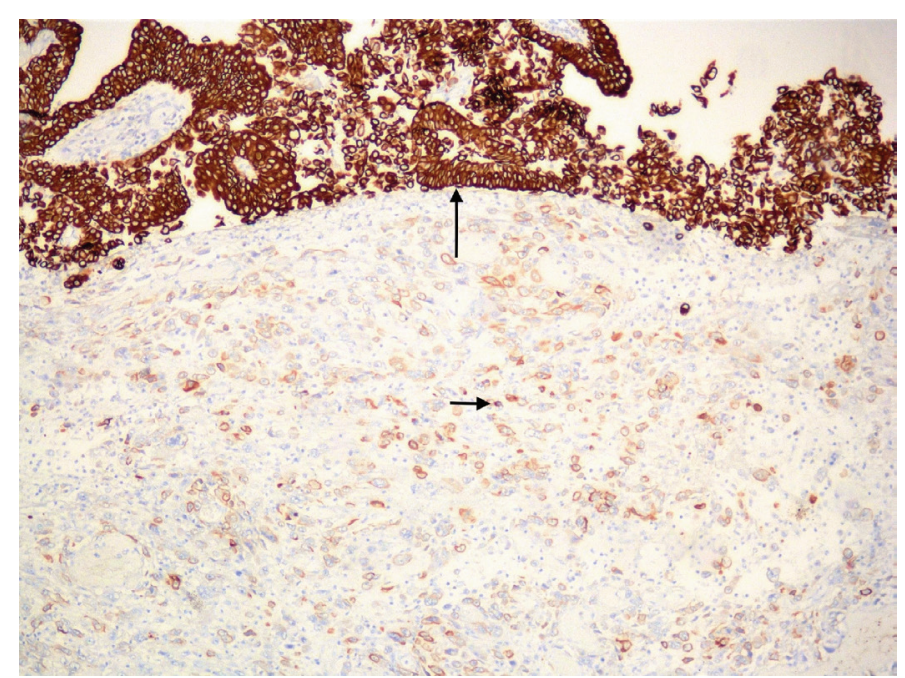

Figure 4. Diffuse strong positive reaction at areas with epithelial differentiation using pancytokeratin (long arrow) and focal immune reaction at areas with mesenchymal differentiation (IHK x 200) IHK: Immunohistochemistry

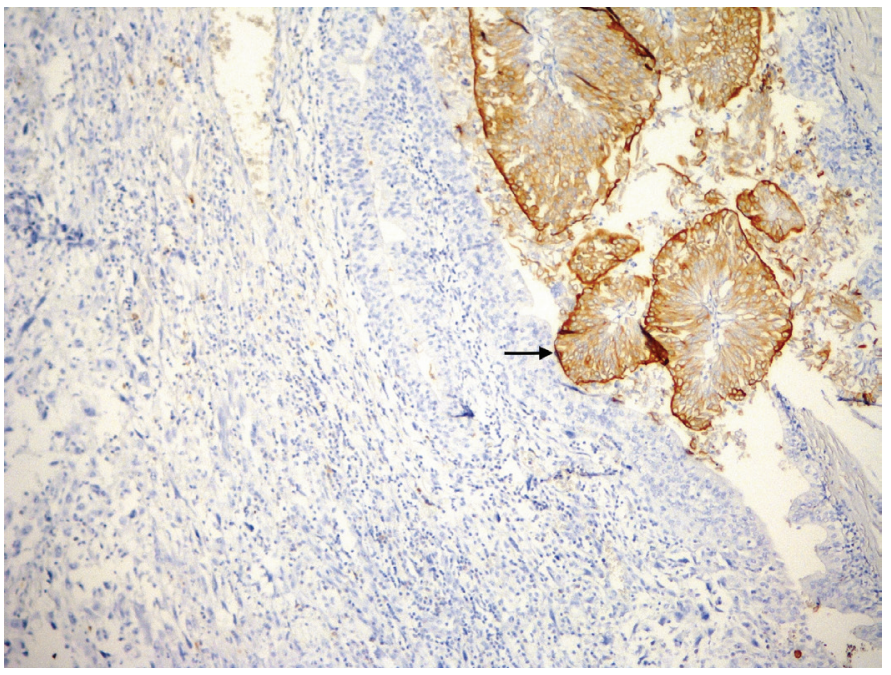

Figure 5. Focal immune reaction at epithelial differentiation areas with CK20 (IHK x 200)

CK: Cytokeratin, IHK: Immunohistochemistry tumors of the urinary system containing epithelial and mesenchymal components. Two hypotheses have been proposed in the histogenesis of sarcomatoid carcinoma by molecular genetic studies. The first of these is the "dedifferentiation theory", which is the altered differentiation of monoclonal tumors, and the second is the "collision theory" which involves the formation of urothelial and mesenchymal tumors synchronously. According to the dedifferentiation theory, the sarcomatous component of sarcomatoid carcinoma is due to the dedifferentiation of some of the urothelial cancer stem cells to the mesenchymal phenotype. Harmonious genetic differentiation in carcinomatous and sarcomatous components and expression of epithelial markers by both components support this hypothesis. The "collision theory" suggests that the carcinomatoid and sarcomatoid components develop separately from urothelial and mesenchymal stem cells. These stem cells cause the development of carcinoma and sarcoma in the same organ at the same time. Today, collision theory has lost its effect, and the dedifferentiation theory is widely accepted (25). Molecular genetic studies in recent years emphasize that the epithelial and mesenchymal components develop from a common monoclonal origin (5). In addition, Armstrong et al. (12) determined that p53 mutation in the epithelial and sarcomatoid component of the bladder sarcomatoid carcinoma is effective in the differentiation of both components in the early stages of tumor development.

Although the age of onset and clinical findings of sarcomatoid carcinoma of the bladder resemble conventional urothelial carcinoma, its prognosis is much worse. Therefore, it should be distinguished from other morphological variants (16). This tumor, which is generally seen in smoking men, has a female: male ratio of 1:3. Although smoking rate varies, a history of smoking was reported by $64 \%$ of the cases in Wang et al. (6) study, and in $88 \%$ of the cases in Başeskioğlu et al. (17) study. In addition, a history of radiotherapy, diabetes mellitus, neurogenic bladder, bladder diverticulum, and cyclophosphamide use are among other risk factors $(26,27)$. In our case, no smoking history and any other risk factors other than male gender were determined. Sarcomatoid carcinoma of the bladder has been reported between the ages of 10 and 96, with an average age of 66. Our case was 75 years old, which was the age range defined in the literature.

The most common symptom of admission in cases of sarcomatoid carcinoma is macroscopic hematuria; other symptoms are dysuria, nocturia, abdominal pain, and urinary tract infection $(11,17,19)$. Our case also applied with macroscopic hematuria. Sarcomatoid carcinoma is usually large at the time of diagnosis, 
and the average size is $6.2(0.6-16) \mathrm{cm}$. The most common location is the lateral wall, fundus and trigon, and bladder floor $(11,16)$. In our case, the tumor mass was $7.5 \times 6.1 \times 1.8 \mathrm{~cm}$ and was larger than the average of the literature. It had a wide distribution involving bladder floor, right and left walls, front and back walls, and trigon. Hemorrhage, necrosis, and cystic areas can be seen on the crosssectional surface of these tumors (25). Although the epithelial component is composed of high-grade invasive urothelial carcinoma in most cases, it may also contain different types of carcinomas, such as squamous cell carcinoma, adenocarcinoma, or small cell carcinoma (28). The mesenchymal component is mostly composed of undifferentiated spindle or pleomorphic cells, rarely may include chondrosarcoma, osteosarcoma, rhabdomyosarcoma, liposarcoma, and angiosarcoma $(3,25)$. In the Lopez-Beltran et al. (11) study, chondrosarcoma was reported to be $20 \%$, leiomyosarcoma $20 \%$, malignant fibrous histiocytoma $20 \%$, osteosarcoma $13.3 \%$, fibrosarcoma $6.7 \%$ and rhabdomyosarcoma $6.7 \%$ for the mesenchymal component. In our case, the mesenchymal component was spindle-shaped in some locations, multinuclear with a giant cell appearance in other locations, and no heterologous element such as muscle, bone, or cartilage was observed. In such tumors, the epithelial component may react to epithelial markers such as pancytokeratin and EMA, while the mesenchymal component may show an immune reaction to the vimentin and epithelial markers as well as the reaction may depend on the heterologous element it contains (1). Since sarcomatoid component is very important in treatment and prognosis, it must be determined by immunohistochemical study. The immunohistochemical panel consisting of pancytokeratin, high molecular weight cytokeratin, p63, vimentin, SMA, and desmin has been shown to be useful in determining epithelial and sarcomatoid components (29). In our case, the results of immunohistochemistry were consistent with the literature. Malignant nonepithelial neoplasms should be considered in the differential diagnosis in small biopsies where sarcomatoid areas occupy a large portion. In this case, it may be necessary to apply a wide immunohistochemistry panel. SMA for inflammatory myofibroblastic tumor, SMA, and lemin

\begin{tabular}{|c|c|c|c|c|c|c|c|}
\hline & $\begin{array}{l}\text { Number of } \\
\text { cases/diagnosis }\end{array}$ & $\begin{array}{l}\text { Smoking } \\
\text { history } \\
(\%)\end{array}$ & $\begin{array}{l}\text { Hematuria } \\
(\%)\end{array}$ & $\begin{array}{l}\text { Mean age } \\
\text { (minimum- } \\
\text { maximum) }\end{array}$ & $\begin{array}{l}\text { Male/female } \\
\text { ratio }\end{array}$ & $\begin{array}{l}\text { Tumor size }(\mathrm{cm}) \\
\text { (minimum- } \\
\text { maximum) }\end{array}$ & $\begin{array}{l}\text { Number of } \\
\text { metastatic lymph } \\
\text { nodes }\end{array}$ \\
\hline Wang et al. (6) & $221 / S C$ & U & U & $75(41-96)$ & 2 & U & 15 \\
\hline Wright et al. (7) & 135 / SC 166 / CS & U & U & U & $\begin{array}{l}1.6 / \mathrm{SC} \\
1.96 / \mathrm{CS}\end{array}$ & U & 23 \\
\hline Young et al. (9) & $12 / \mathrm{SC}$ & U & 75 & $71.5(60-83)$ & 1.4 & U & U \\
\hline Wang et al. (10) & $14 / S C$ & 64 & 100 & $63(45-93)$ & 6 & $4.5(0.6-8)$ & 50 \\
\hline Lopez-Beltran et al. (11) & $\begin{array}{l}26 / S C \\
15 / C S\end{array}$ & U & $\begin{array}{l}70 / S C \\
77 / C S\end{array}$ & $66.5(41-91)$ & $\begin{array}{l}4.2 / \mathrm{SC} \\
2 / \mathrm{CS}\end{array}$ & $\begin{array}{l}6.2 / \mathrm{SC} \\
7.8 / \mathrm{CS}\end{array}$ & $\begin{array}{l}15 / S C \\
20 / C S\end{array}$ \\
\hline Guo et al. (15) & $87 / S C$ & U & 84 & $66(18-89)$ & 3.8 & $72 \%>3 \mathrm{~cm}$ & U \\
\hline Ikegamı et al. (16) & $14 / S C$ & U & U & $76(50-82)$ & 1.8 & 3 & U \\
\hline Torenbeek et al. (1) & $18 / \mathrm{SC}$ & U & 94 & $72(49-88)$ & 2.6 & $4.5(2-10)$ & 44 \\
\hline Başeskioğlu et al. (17) & $14 / S C$ & 88 & 100 & $65(41-86)$ & 6 & $5.5(3-16)$ & 21 \\
\hline Jones and Young (18) & $25 / S C$ & U & U & $72(50-92)$ & 1.3 & $6.8(3-15)$ & U \\
\hline Perret et al. (19) & $8 / \mathrm{SC}$ & U & 100 & $70(50-85)$ & 1.67 & $5(2-10)$ & U \\
\hline Wang et al. (20) & $1 / \mathrm{SC}$ & U & 100 & 10 & Female & 6 & No \\
\hline Bernardes Filho et al. (21) & $1 / \mathrm{SC}$ & U & 100 & 63 & Male & 10 & U \\
\hline Sanfrancesco et al. (22) & $28 / S C$ & U & U & $70(45-92)$ & $17 / 11$ & U & 10 \\
\hline
\end{tabular}


for leiomyosarcoma, CD34, and STAT6 for perivascular epiteloid cell tumor, CD31 and CD34 for solitary fibrous tumor, CD31 and CD34 for vascular tumors, are the main immunomarkers to be used in the differentiation of nonepithelial neoplasia $(22,30,31)$.

Nodal and distant metastasis, which are determined at $10 \%$ in urothelial carcinoma is above $20 \%$ in sarcomatoid carcinoma. In the literature, tumor metastasis was detected in most of the cases with a diagnosis of sarcomatoid carcinoma in which lymph node was dissected, and tumor metastasis was detected in one left and one right pelvic lymph nodes in our case. This tumor has a worse prognosis than advanced stage urothelial carcinoma (7). There is no standard treatment for sarcomatoid carcinoma yet, as it is a rare variant, and no randomized controlled trials are available. Multidisciplinary treatment consisting of surgery, local radiotherapy, and chemotherapy is applied in locally advanced tumors. Although radical cystoprostatectomy is recommended in surgical treatment, Özkan et al. (28) performed partial cystectomy because their patients refused radical surgery, and they did not detect recurrence in their 24-month follow-up. In the 80-year-old metastatic sarcomatoid carcinoma case reported by Froehner et al. (32), gemcitabine and cisplatin were used as systemic chemotherapy and local and distant remission was achieved. Local recurrence and distant metastasis were not detected in the patient who was followed by Onal et al. (33) with adjuvant RT treatment after total cystectomy. The effect of radiotherapy alone has not been demonstrated in this tumor (11). Adjuvant radiotherapy indications have been reported as high grade tumors, extravesical extension, surgical margin positivity, lymph node metastasis, and lymphovascular invasion (34). Five-year disease-free survival is 20\% (27). The most important predictive factors for long-term survival are surgical margins and metastasis. The prognosis is poor in cases with metastasis. In the study in which Lopez-Beltran et al. (11) examined 41 cases, the average survival was 10 months. According to the latest SEER data analysis, the most important predictive factor in survival was the pathological stage. In our case, a body scan was performed, and distant metastasis was not detected. Our case didn't take any treatment after the operation, her general condition was deteriorated, and she died after 2.5 months.

\section{CONCLUSION}

In conclusion, it is important to keep in mind the sarcomatoid carcinoma, which has a more aggressive course and shorter survival compared to urothelial carcinoma in order to determine the correct diagnosis and the most appropriate treatment approach. In particular, taking multiple samples from large tumors is important to identify different components such as our patient, who initially appeared to have only high-grade urothelial carcinoma. The most important factor which determines survival is the pathological grade. Multidisciplinary treatment consisting of surgery, chemotherapy, and radiotherapy should be tailored by evaluating the stage of the disease and the general condition of the patient.

\section{Ethics}

Peer-review: Externally peer-reviewed.

\section{Authorship Contributions}

Surgical and Medical Practices: Ö.G., A.Ö., Concept: Ö.G., S.B., Design: S.B., Data Collection or Processing: Ö.G., S.B., A.Ö., Analysis or Interpretation: Ö.G., A.Ö., Literature Search: Ö.G., S.B., Writing: Ö.G., S.B., A.Ö.

Conflict of Interest: No conflict of interest was declared by the authors.

Financial Disclosure: The authors declared that this study received no financial support

\section{REFERENCES}

1. Torenbeek R, Blomjous CE, de Bruin PC, Newling DW, Meijer CJ. Sarcomatoid carcinoma of the urinary bladder. Clinicopathologic analysis of 18 caseswith immunohistochemical and electronmicroscopic findings. Am J SurgPathol 1994;18:241-9.

2. Venyo AK, Titi S. Sarcomatoid variant of urothelial carcinoma (carcino sarcoma, spindle cell carcinoma): a review of the literature. ISRN Urol 2014:794563.

3. Amin MB. Histological variants of urotelial carcinoma: diagnostic, therapeutic and prognostic implications. Modern Pathol 2009;22(Suppl 2):96-118

4. Reuter VE. Sarcomatoid lesions of the urogenital tract. Semin Diagn Pathol 1993;10:188-201

5. Malla M, Wang J, Trepeta R, Feng A, Wang J. Sarcomatoid carcinoma of the urinary bladder. Clin Genitourin Cancer 2016;14:366-72.

6. Wang J, Wang FW, Langrange CA, Hemstreetlii GP, Kessinger A. Clinical features of sarcomatoid carcinoma (carcinosarcoma) of the urinary bladder: analysis of 221 cases. Sarcoma 2010:2010.

7. Wright JL, Black PC, Brown GA, Porter MP, Kamat AM, Dinney CP, et al Differences in survival among patients with sarcomatoid carcinoma, carcinosarcoma and urothelial carcinoma of the bladder. J Urol 2007:178:2302-6

8. Spiess PE, Tuziak T, Tibbs RF, Bassett R, Tamboli P, Brown GA, et al. Pseudosarcomatous and sarcomatous proliferations of thebladder. Hum Pathol 2007;38:753-61.

9. Young RH, Wick MR, Mills SE. Sarcomatoid carcinoma of the urinary bladder: a clinicopathologic analysis of 12 cases and review of the literatüre. Am J Clin Pathol 1988;90:653-61. 
10. Wang J, Gillaspie C, Kunadharaju R, Talmon GA, Enke C. Sarcomatoid urothelial carcinoma: a single cancer center experience. World J Oncol 2011;4:175-80.

11. Lopez-Beltran A, Pacelli A, Rothenberg HJ, Wollan PC, Zincke H, Blute ML, et al. Carcinosarcoma and sarcomatiod carcinoma of the bladder: clinicopathological study of 41 cases. J Urol 1998;159:1497-503.

12. Armstrong AB, Wang M, Eble JN, MacLennan GT, Montironi R, Tan PH, et al. TP53 mutational analysis supports monoclonal origin of biphasic sarcomatoid urothelial carcinoma (carcinosarcoma) of the urinary bladder. Mod Pathol 2009;22:113-8.

13. Sung MT, Wang M, MacLennan GT, Eble JN, Tan PH, Lopez-Beltran A, et al. Histogenesis of sarcomatoid urothelial carcinoma of the urinary bladder: evidence for a common clonal origin with divergent differentiation. J Pathol 2007;211:420-30.

14. Monn MF, Kaimakliotis HZ, Pedrosa JA, Cary KC, Bihrle R, Cheng L, et al. Contemporary bladder cancer: variant histology may be a significant driver of disease. Urol Oncol 2015;33:18.

15. Guo AT, Huang H, Wei LX. Clinicopathological characteristics and prognosis of Chinese patients with sarcomatoid carcinoma of the bladder. Histol Histopathol 2013;28:1167-74.

16. Ikegamı H, Iwasakı H, Ohjımı Y, Takeuchı T, Arıyoshı A, Kıkuchı M. Sarcomatoid Carcinoma of the Urinary Bladder: A Clinicopathologic and Immunohistochemical Analysis of 14 Patients. Hum Pathol 2000;31:332-40

17. Başeskioğlu B, Duman BB, Kara IO, Can C, Yıldııım M, Açıkalın M. Early Detection and Gemcitabine/Cisplatin Combination Positively Effect Survival in Sarcomatoid Carcinoma of the Urinary Bladder. Asian Pac J Cancer Prev 2012;13:5729-33.

18. Jones EC, Young RH. Myxoid and sclerosing sarcomatoid transitional cell carcinoma of the urinary bladder: a clinicopathologic and immunohistochemical study of 25 cases. Mod Pathol 1997;10:908-16.

19. Perret L, Chaubert P, Hessler D, Guilou L. Primary heterologous carcinosarcoma (metaplastic carcinoma) of the urinary bladder: clinicopathologic, immunohistochemical, ultrastructural analysis of eight cases and a review of the literature. Cancer 1998;82:1535-49.

20. Wang Z, Xıong W, Pan C, Zhu L, Wang X, Huang Z, et al. Aggressive muscle-invasive bladder cancer with sarcomatoid differantiation in a 10-year-old girl: A case report. Exp Ther Med 2016;11:985-7.

21. Bernardes Filho F, de Melo AS, Pires AR, Lupi O, das Neves DG, da Cruz $\mathrm{MF}$, et al. Cutaneus invasion from sarcomatoid urothelial carcinoma: clinical and dermatopathologic features. An Bras Dermatol 2016;91:739 .
22. Sanfrancesco J, McKenney JK, Leivo MZ, Gupta S, Elson P, Hansel DE. Sarcomatoid urotelial carcinoma of the bladder. Analysis of 28 cases with emphasis on clinicopathologic features and markers of epithelialto-mesenchymal transition. Arch Pathol Lab Med 2016;140:543-51.

23. Yasui M, Morikawa T, Nakagawa T, Miyakawa J, Maeda D, Homma Y, et al. Urinary bladder carcinoma with divergent differentiation featureing small cell carcinoma, sarcomatoid carcinoma, and liposarcomatous component. Pathol Res Pract 2016;9:833-7.

24. Lembo F, Subbo E, Lagana AS, Vitale SG, Valenti G, Magno C. Intradiverticular sarcomatoid carcinoma of the bladder: an overview starting from a peculiar case. Urol J 2016;13:2800-2.

25. Cheng L, Zhang S, Alexander R, Maclennan GT, Hodges KB, Harrison BT, et al. Sarcomatoid carcinoma of the urinary bladder: the final common pathway of urothelial carcinoma dedifferentiation. Am J Surg Pathol 2011;35:34-46

26. Young RH, Eble JN. Unusual forms of carcinoma of the urinary bladder. Human Pathol 1990;22:948-65.

27. Dahm P, Gschwend JE. Malignant non-urotelial neoplasms of the urinary bladder: a review. Eur Urol 2003;44:672-81.

28. Özkan A, Balcı MBC, Hazar Ai, Gezmiş CT, Kurtuluş FO, Nuhoğlu B. Mesanenin Sarkomatoid ve Lenfoepitelyoma Benzeri Diferansiye Karsinomu: Parsiyel Sistektomi Olgu Sunumu. J Acad Res Med 2014;1:357.

29. Bruner ET, Stuppi E, Smith T. Sarcomatoid carcinoma of the urinary bladder: case report and review. Int J Exp Pathol 2016;21:274-8.

30. Westfall DE, Folpe AL, Paner GP, Oliva E, Goldstein L, Alsabeh R, et al. Utility of a comprehensive immunohistochemical panel in the differential diagnosis of spindle cell lesions of the urinary bladder. Am J Surg Pathol 2009;33:99-105.

31. Hodges KB, Lopez-Beltran A, Emerson RE, Montironi R, Cheng L. Clinical utility of immunohistochemistry in the diagnoses of urinary bladder neoplasia. Appl Immunohistochem Mol Morphol 2010;18:401-10.

32. Froehner M, Gaertner HJ, Manseck A, Wirth MP. Durable complete remission of metastatıc sarcomatoid carcinoma of the bladder with cisplatin and gemcıtabıneın an 80-year-old man. Urology 2000;58:799.

33. Onal C, Pehlivan B, Bal N, Topkan E, KilincF, Topuk S. Sarcomatoid carcinoma of the Urinary Bladder Treated with Adjuvant Radiotherapy: A case Report. Clin Med Case Rep 2009;2:39-42.

34. Bansal A, Kumar N, Sharma SC. Sarcomatoid variant of urothelial carcinoma of the urinary bladder. J Cancer Res Ther 2013;9:571-3. 